\title{
Paciente de 70 años con dolor en fosa ilíaca izquierda y crepitación a la palpación profunda abdominal
}

\author{
M. J. Menduiña Guillén, P. Alaminos García y M. Valenzuela Barranco \\ Departamento de Medicina. Universidad de Granada. Granada
}

\section{CASO CLÍNICO}

Paciente de 70 años de edad sin antecedentes de interés, acude a urgencias aquejado de pérdida ponderal de $15 \mathrm{~kg}$, astenia intensa, anorexia y estreñimiento desde hace 2 meses. En el transcurso de la última semana presenta además, importante dolor cólico en hemiabdomen izquierdo con escasa mejoría a analgésicos habituales. En la exploración física destaca aceptable estado general, palidez mucocutánea, auscultación cardiorrespiratoria sin alteraciones y abdomen blando y depresible con dolor a la palpación profunda, así como palpación de masa de 5-6 cm de diámetro en cuadrante inferior izdo. En la analítica de ingreso, destaca: Hb: 10.8 g, Hcto: 38\%, VCM: 78, leucocitos: 13.600/ul, con neutrofilia, Fe: 8, úrico: 9,6, LDH: 876 y resto de parámetros dentro de la normalidad. En la Rx de tórax y abdomen no se aprecian alteraciones significativas.

A las 8 horas de su ingreso, se agudiza de manera importante el dolor en fosa ilíaca izquierda, irradiándose este a la zona centroabdominal. En la exploración física presenta, además de la referida sensación de masa, una crepitación difusa en toda la pared abdominal y signos de peritonismo. Se realiza un TAC abdominal urgente, en el que se observa (Figs. 1 y 2): dilatación de asas intestinales producida por la presencia de masa sólida de unos $10 \mathrm{~cm}$ de diámetro máximo, situada en pelvis izquierda, que condiciona estenosis y obstrucción intestinal a nivel del sigma. La masa, de contornos mamelonados infiltra el músculo ilíaco izquierdo, y en su porción superior parece ulcerada y fistulizada a pared abdominal anterior, la cual está marcadamente engrosada, con aire y colección líquida, más evidente en el lado izquierdo.

Diagnóstico: neoplasia de sigma fistulizada a pared abdominal, con abscesificación. Enfisema de pared abdominal.

El paciente evoluciona desfavorablemente, presentando un shock séptico refractario al tratamiento durante la intervención quirúrgica, falleciendo horas después. En la necropsia se corroboran los diagnósticos realizados con la prueba de imagen, así como la neoplasia de colon que resultó ser un adenocarcinoma.

\section{COMENTARIO}

En nuestro medio, el cáncer de colon ocupa el segundo lugar en frecuencia. Se dice que alrededor un 5\% de la población general desarrollará un cáncer colono-rectal a lo largo de su vida. Su curva de incidencia es muy baja por debajo de

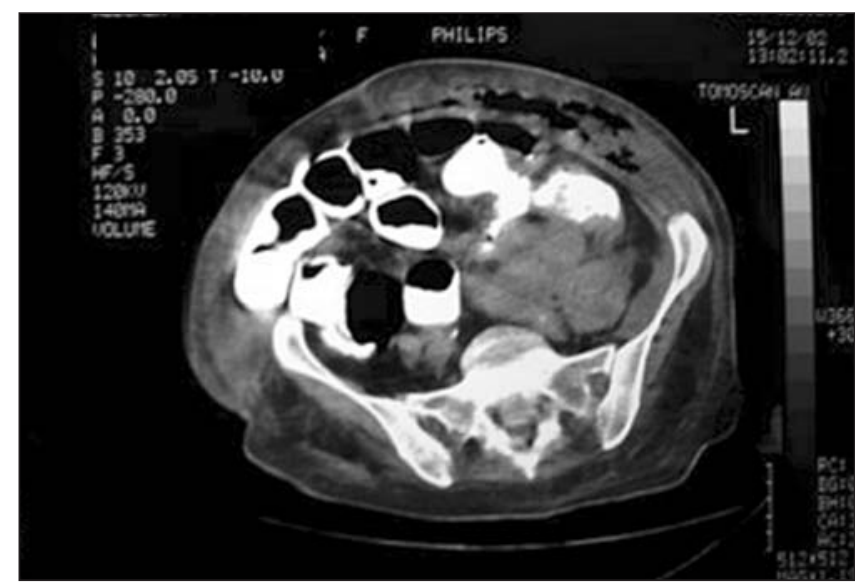

Fig. 1.

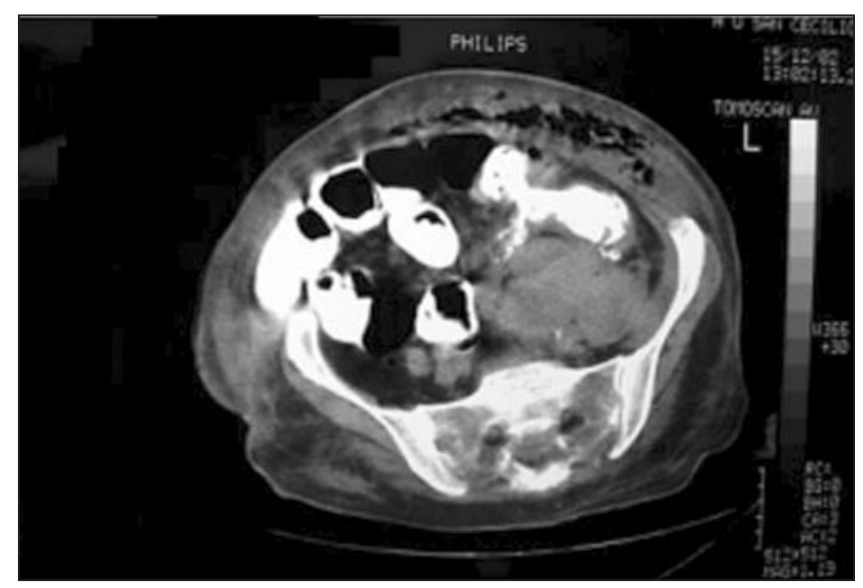

Fig. 2. 
los 40 años, alcanzando un pico importante entre los 75 y 80 años. Se estima que dos tercios de estos cánceres se localizan en la zona recto-sigmoidea. El diagnóstico de esta patología debe basarse en una buena historia clínica en la que se recojan datos de síndrome constitucional o tóxico, cambios del hábito intestinal, antecedentes personales y familiares. Es importante realizar una minuciosa exploración física y una colonoscopia total con toma de biopsias. La presentación de un adenocarcinoma de sigma como un cuadro abdominal agudo con enfisema de la pared abdominal, secundario a fistulización, no es una presentación clínica habitual, pudiéndose considerar como una complicación grave de esta neoplasia (1). Si es más frecuente esta presentación clínica en otras patologías del colon como es el caso de las diverticulitis complicadas (2), o como complicación de una colonoscopia diagnóstica o terapeútica (3); situaciones en que la perforación del colon puede fistulizar a la pared abdominal, permitiendo el paso de gas procedente del colon al espesor de ésta.

En este tipo de patologías tiene especial importancia el diagnóstico por imagen, basado fundamentalmente en la ecografía y en la TAC abdominal. La primera puede servirnos en una primera aproximación diagnóstica dado que la patología de la pared abdominal suele detectarse bien ecográficamente (4), pero es sin duda la TAC con contraste oral la prueba diagnóstica por excelencia, dado que nos permite además visualizar toda la pared del colon, aunque para ello a veces es necesario cambiar al paciente de posición desde decúbito prono a supino para realizar una exploración completa. Además, esta última postura nos permite ver el gas que se desplaza a la parte alta de la pared abdominal (5).

\section{BIBLIOGRAFÍA}

1. Walker MJ, Mozes MF. Massive subcutaneous emphysema: an unusual presentation of jejunal perforation. Am Surg 1981 ; 47 (1): $45-8$.

2. Lai W, Dowell J. Images in clinical medicine. Diffuse subcutaneous air due to a perforated colonic diverticulum. N Engl J Med $2004 ; 350$ (13): e12.

3. Ker TS, Wasserberg N, Beart RW Jr. Colonoscopic perforation and bleeding of the colon can be treated safely without surgery. Am Surg 2004; 70 (10): 922-4.

4. Yeh HC, Rabinowitz JG. Ultrasonography and computed tomography of inflammatory abdominal wall lesions. Radiology 1982; 144 (4): $859-63$.

5. Svensson MH, Svensson E, Hellstrom M. Bowel wall visualisation at CT colonography. Acta Radiol 2002; 43 (1): 87-95. 